Western University Scholarship@Western

French Studies Publications

French Studies Department / Département d'études

françaises

2-2009

\title{
External Possession Meets Bare Nouns in Malagasy
}

Ileana Paul

The University of Western Ontario, ileana@uwo.ca

Follow this and additional works at: https://ir.lib.uwo.ca/frenchpub

Part of the French and Francophone Language and Literature Commons, and the Syntax Commons

Citation of this paper:

Paul, Ileana, "External Possession Meets Bare Nouns in Malagasy" (2009). French Studies Publications. 66.

https://ir.lib.uwo.ca/frenchpub/66 


\title{
External possession meets bare nouns in Malagasy*
}

\author{
Ileana Paul
}

University of Western Ontario

\begin{abstract}
This paper examines apparent noun incorporation in Malagasy that is the result of external possession (possessor raising). It is shown that such incorporation is not derived via head movement or via compounding. Instead, it is argued that this is an instance of pseudo noun incorporation (Massam 2001): the possessum is merged as an NP sister to the predicate. As for the structure of external possession, a non-movement analysis is proposed: the apparent possessor is generated as the specifier of a null possessive head and binds an empty argument position within the possessum. The resulting structure and meaning are shown to be parallel to experiencer 'have' constructions in English.
\end{abstract}

\section{Introduction}

In her classic paper on noun incorporation, Mithun (1984) documents several cases of noun incorporation involving body parts. That is, the incorporated noun is a body part and the possessor appears as a separate constituent. These examples of noun incorporation are thus a subset of cases of external possession (possessor raising). ${ }^{1}$ In this paper, I look at similar data from Malagasy, data discussed in detail by Keenan and Ralalaoherivony (2000) (henceforth $\mathrm{K} \& \mathrm{R})$ under the general rubric of "raising from NP". 2

\footnotetext{
* I would first like to thank the Malagasy speakers who very patiently helped me with the data: Saholy Hanitriniaina, Emma Mamifarananahary, Hasina Mihaingosoa, Dina Rakoto-Ramambason, Hanta Rakotoarivony, Georges Ralaisoa, Vololona Rasolofoson, Francine Razafimboaka. Unless otherwise indicated, all data are from my own fieldwork. I would also like to thank the two anonymous reviewers for their insightful questions and constructive suggestions. Finally, I would like to acknowledge the generous feedback from participants at the Workshop on Comparative Austronesian Syntax, the Nominal Incorporation and its Kind conference, the Nudist(e) workshop on bare nouns, AFLA XI and the Bilingual Workshop in Theoretical Linguistics. Any errors remain my own.

${ }^{1}$ I will use the term "external possession" because it does not presuppose an analysis, unlike the somewhat more common "possessor raising". See Payne and Barshi (1999) for a collection of papers on this topic.

${ }^{2}$ For uniformity, I have slightly modified the glosses and translations of the K\&R examples. Travis (2001) also discusses external possession in Malagasy and concludes that there are two types - true raising and pseudo-raising. The analysis presented here takes all cases to be pseudo-raising. Abbreviations used in this paper:

\begin{tabular}{|l|l|l|l|}
\hline ACC - accusative & AT - actor topic & CT - circumstantial topic & DEF - definite determiner \\
\hline DET - specific determiner & FOC - focus particle & FUT - future & GEN - genitive \\
\hline NEG - negation & NOM - nominative & P - preposition & PST - past \\
\hline RECIP - reciprocal & SUPER - superlative & TOP - topic particle & TT - theme topic \\
\hline
\end{tabular}
}


a. Rovitra ny vodin'ny harona.

torn $\quad$ DET bottom.GEN.basket

'The bottom of the basket is torn.'

b. Rovi-body ny harona.

torn-bottom DET basket

'The basket has a torn bottom.'

[K\&R: (4b)]

In (1a), the possessor ny harona surfaces as a genitive phrase within the subject DP headed by vody 'bottom'. In (1b), the external possession counterpart, ny harona is the nominative subject and vody 'bottom' surfaces as a bare noun lacking a determiner. ${ }^{3}$ In both cases, rovitra 'torn' is the main predicate. ${ }^{4} \mathrm{~K} \& \mathrm{R}$ point out that when the relevant phonological conditions are met, the possessum may appear "incorporated" into the main predicate. ${ }^{5}$ To keep the terminology as clear as possible, I will refer to this phonological process as "bonding". (2a) illustrates a typical case where such bonding is optional and (2b) provides an example where the phonological environment for bonding is not met (see section 3 for more detail).

a. Tapaka fe izy. OR Tapa-pe izy.

broken leg 3(NOM)

'He has a broken leg.'

[K\&R: (22a)]

b. Marary kibo aho.

sick belly $1 \mathrm{SG}(\mathrm{NOM})$

'I am sick in the stomach.'

[K\&R: (4a)]

\footnotetext{
${ }^{3}$ Common nouns in Malagasy are number neutral - the noun harona 'basket' in (1) could be interpreted as singular or plural.

${ }^{4}$ Note that in examples of external possession such as (1b), the initial adjective (or verb) is the main predicate; it is not a modifier of the following noun. Malagasy is a strongly head-initial language; modifying adjectives/verbs therefore come after the head noun, as in (i).

(i) ny vody rovitra DET bottom torn 'the torn bottom'

${ }^{5} \mathrm{~K} \& \mathrm{R}$ argue neither for raising nor for incorporation, if these terms are taken to describe syntactic movement. Instead, because their goal is to describe the range of external possession rather than to provide a syntactic analysis, they use both of these terms descriptively.
} 
In (2a), the noun $f e$ 'leg' can be bonded to the predicate tapaka 'broken', whereas in (2b) no bonding occurs. Nevertheless, in both examples the noun forms a single phonological unit with the predicate.

Two questions arise immediately: first, is bonding a signal of incorporation? Second, if there is incorporation, what kind of incorporation is it (syntactic, lexical, etc.)? Third, what is the structure of external possession? As an answer to the first question, I assume that a bare noun possessum is incorporated into the predicate, whether or not phonological bonding actually occurs (see section 3 for some motivation for this assumption). The bulk of the paper considers the other two questions.

Noun incorporation has been analyzed in the literature as either involving syntactic movement (e.g. Baker 1988) or base generation (compounding) (e.g. Rosen 1989). Under Baker's analysis, a noun undergoes head movement in the syntax and adjoins to a verb head. According to Rosen, on the other hand, noun incorporation is a kind of compounding and is formed in the lexicon, not in the syntax. More recently, the range of incorporation types has been broadened to include what Massam (2001) calls "pseudo noun incorporation": a verb takes an NP rather than a DP complement and the two form a unit that may (e.g. in Niuean) undergo predicate fronting. Thus while the verb and its object form a constituent, the object itself can be larger than a head, which leads Massam to reject a head movement analysis. A close examination of the Malagasy data leads me to eliminate both a head movement and a compounding analysis. Instead, I propose that the possessum is generated as an NP sister to the predicate and as such it can undergo a rule of phonological bonding, as in (2a). The resulting structure is therefore an instance of pseudo noun incorporation. ${ }^{6}$

This paper also explores the interpretation of the bare possessum. Unlike other bare nouns in Malagasy, it appears to scope above negation. On the other hand, the bare possessum patterns with other bare nouns in scoping under other adverbs such as indroa 'twice' and lalandava 'always'. I tentatively suggest that the referentiality of the bare possessum stems from the presence of the null 'have' head, which binds the referential index of the NP, much like a

\footnotetext{
${ }^{6}$ Note that all bare noun direct objects in Malagasy can be analyzed as pseudo noun incorporation. In this paper, I only consider external possession, but the analysis extends to a wider range of cases. See Paul (to appear) for discussion.
} 
determiner. Malagasy external possession thus patterns with existential pseudo noun incorporation in Niuean (Massam 2001).

External possession is typically treated as an ascension rule in the Relational Grammar literature (e.g. Bell 1983). In subsequent Government and Binding analyses, movement was eschewed for theory-internal reasons (such movement would violate the Projection Principle) (e.g. Massam 1985, Borer and Grodzinsky 1986). In the past decade, both movement analyses (e.g. Landau 1999) and non-movement analyses (e.g. Van Geenhoven 2002) have been proposed. In this paper, I argue against a movement analysis of Malagasy external possession. In particular, I argue that there is no derivational relation between (1a) and (1b). Instead, I propose that in (1b) the possessor is base generated in a $v \mathrm{P}$ headed by the null equivalent of English 'have'. The argument introduced by this $v$ is interpreted as an entity in a certain relationship with the complement of $v$. The relationship is determined via binding of an empty argument position within the complement (e.g. the possessor argument of an inalienable noun). I suggest that external possession in Malagasy is similar to the so-called "experiencer have" construction in English (see Ritter and Rosen 1997, Harley 1998 and McIntyre 2006).

Asterix had Obelix drop a menhir on him.

In both English and Malagasy, there is an obligatory binding relationship between the subject and some element in the predicate. In English, the bound element is an overt pronoun, while in Malagasy it is obligatorily null.

\section{Background on Malagasy}

Before looking at noun incorporation and external possession in more detail, I provide some relevant background in Malagasy clause structure. Malagasy is a western Austronesian language spoken in Madagascar by approximately 13 million people. The word order, which is fairly rigid, is VOS, as seen in (4) (the subject is marked with a dotted underline). Another striking feature of Malagasy is the verbal voice morphology, which indicates the "role" of the subject. (4) illustrates the standard voice paradigm for the root tapaka 'cut'. Actor Topic morphology (usually the prefix $a n$ - or $i$-), as in (4a), indicates an agent subject; Theme Topic morphology (here the suffix $-i n a)$ in (4b) indicates a theme subject; Circumstantial Topic morphology (a circumfix consisting 
of AT morphology and a suffix -ana) in (4c) indicates that some other role is in subject position (e.g. instrument, time, location). Important for this paper is the fact that the non-AT agent is marked by genitive case and appears adjacent to the verb $(4 b, c)$.

(4) a. Actor Topic (AT)

Nanapaka ity hazo ity tamin'ny antsy i Sahondra.

PST.AT.cut this tree this PST.P'DET knife Sahondra

'Sahondra cut this tree with the knife.'

b. Theme Topic (TT)

Notapahin'i Sahondra tamin'ny antsy ity hazo ity.

PST.TT.cut.GEN.Sahondra PST.P'DET knife this tree this

'This tree was cut by Sahondra with the knife.'

c. Circumstantial Topic (CT)

Nanapahan'i Sahondra ity hazo ity ny antsy.

PST.CT.cut.GEN.Sahondra this tree this DET knife

'The knife was used by Sahondra to cut the tree.'

The precise nature of the so-called voice system is the subject of much debate in the literature (see Pearson 2005 for a recent discussion). For present purposes, I will continue to call this verbal morphology "voice", because it has no effect on the analysis proposed in this paper. Similarly, the status of the clause-final argument is hotly disputed in current research on Malagasy. Some refer to it as a subject (an A position) (e.g. Guilfoyle, Hung and Travis 1992) and others as a topic (an A-bar position) (Pearson 2005). This difference will not be important here.

The structure of VOS word order in Malagasy is also much debated, in particular since the antisymmetry hypothesis of Kayne (1994). Not only are subjects in an apparent rightward specifier, but adverbials seem to be in right-adjoined positions. To simplify presentation of my analysis, I assume a non-Kaynean structure rather than the more popular predicate-fronting and "roll-up" structures proposed in Pearson (2001), Rackowski and Travis (2000) and others. The 
ordering of arguments and adjuncts in Malagasy and Niuean pose non-trivial difficulties for these types of analysis, as discussed by Massam (2006) and Thiersch (2006). These questions about phrase structure are surely empirical, but the analysis presented in this paper can easily be transposed into an antisymmetrical system with no loss of the core ideas (e.g. pseudo noun incorporation).

Before continuing, I note that it is also possible to have non-verbal categories serving as the main predicate, as illustrated in (6). These examples illustrate that Malagasy lacks a copular verb.

(5)a. [Vorona ratsy feo $]_{\mathrm{NP}}$ ny goaika bird bad voice DET crow 'The crow is a bird with an ugly voice.'

b. [Faly amin'ny zanany $]_{\mathrm{AP}}$ Rasoa proud P'DET child.GEN.3SG Rasoa 'Rasoa is proud of her children.'

c. [Any an-tsena $]_{\mathrm{PP}}$ Rakoto P ACC-market Rakoto 'Rakoto is at the market.'

In this paper, we will see many examples of adjectives acting as main predicates. For reasons of simplicity, I do not posit a null copula - such a copula may indeed be present in examples such as (5).

\section{Incorporation}

As mentioned above, external possession in Malagasy sometimes triggers what $\mathrm{K} \& \mathrm{R}$ call incorporation (what I have been calling bonding). As I noted, we may ask if bonding signals 
incorporation and if so, what kind of incorporation is involved? I illustrate with (6) and (7), where bonding is optional. ${ }^{7}$

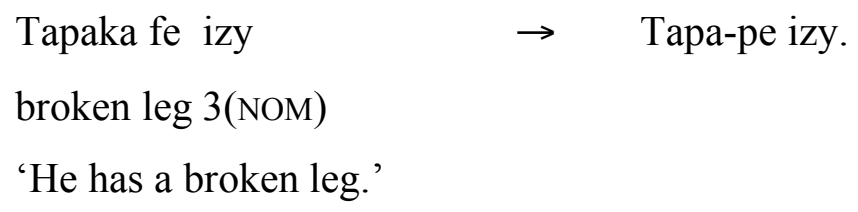

[K\&R: (22a)]

(7) Maranitra saina Rabe. $\quad \rightarrow \quad$ Marani-tsaina Rabe. sharp mind Rabe

'Rabe is sharp minded.'

[K\&R: (31a)]

Simplifying somewhat, bonding may occur when the predicate ends in $-n a,-k a$, or $-t r a$. This syllable is dropped and an initial continuant of the following words becomes the corresponding non-continuant (Keenan and Polinksy 1998). The resulting string is a single prosodic word with one main stress. As a second indication of the tight dependency between the predicate and the noun, adverbs cannot separate the two, even when bonding does not occur, as shown by the contrast in (8).
a. Fotsy nify tokoa izy.
white tooth especially $3(\mathrm{NOM})$
'She really has white teeth.'
b. * Fotsy tokoa nify izy. white especially tooth $3(\mathrm{NOM})$

[K\&R: $\left.\left(20 b, b^{\prime}\right)\right]$

The data in (6) - (8) provide evidence in favour of incorporation of the possessum into the predicate, even when bonding is absent. The next section discusses the nature of this incorporation.

\footnotetext{
${ }^{7}$ For reasons that are not yet clear to me, in certain cases bonding is obligatory and in others it is impossible. In the descriptive literature, it is described as optional.
} 


\subsection{What incorporation isn't}

Consider now two possible analyses of incorporation. First, one could adopt a head movement approach, à la Baker (1988). Abstracting away from other details of phrase structure, the noun possessum undergoes head movement and adjoins to the main predicate:

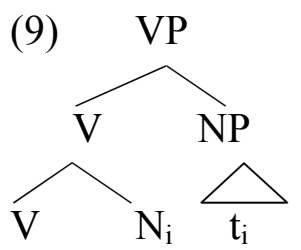

Although this analysis is appealing, it can be shown that examples such as (6) - (8) do not involve head movement. For example, there are ample cases that illustrate that the noun in external possession need not be a head - it can be modified (10a,b,c) and even coordinated (10d).

$\begin{array}{lll}\text { a. Maty zanaka } & \text { hendry } & \text { Rabe. } \\ \text { dead child } & \text { wise } & \text { Rabe }\end{array}$

'Rabe suffers the death of his well-behaved child.'

[K\&R: (32a)]

b. Very kirarao mafy toto Rabe.

lost shoe hard pounding Rabe

'Rabe suffers the loss of his force-withstanding shoes.' [K\&R: (32c)]

c. Maty zanaka izay efa lehibe Rabe.

dead child REL already big Rabe

'Rabe suffers the death of his child who was already big.

d. Maty vady aman-janaka Rakoto.

dead spouse with-child Rakoto

'Rabe suffers the loss of his wife and child.'

Given that the incorporated element can be phrasal, examples such as these argue against a headmovement analysis of incorporation in Malagasy. 
Consider now the compounding analysis. Under this approach, noun incorporation is formed in the lexicon. The Malagasy examples would therefore be parallel to English sentences such as (11a). In other words, in (11b) the main predicate is fotsy nify 'white-toothed' and this is predicated of the subject Rabe.
a. Rabe is rosy-cheeked.
b. [[Fotsy nify] Rabe].
white tooth Rabe
'Rabe is white-toothed.'

The problem with the compounding analysis is that despite the close bond between the predicate and the incorporated NP, certain elements can come in between the two. Recall that in non-AT clauses, the agent surfaces as a genitive adjacent to the verb. If an instance of external possession occurs in the non-active, as in (12b), a genitive agent separates the predicate from the bare NP. ${ }^{8}$
a. Manety
volo an-janany
Rabe.
AT.cut hair ACC-child.3(GEN) Rabe
'Rabe cuts his child's hair.'
b. Hetezan-dRabe volo ny zanany.
TT.cut.GEN.Rabe hair DET child.3(GEN)
'His child has his hair cut by Rabe.

[K\&R: (60a'),(48a')]

If manety volo were a compound predicate formed in the lexicon, we would not expect the genitive agent to surface between the two roots. The grammaticality of (12b) therefore shows that incorporation cannot be an instance of compounding.

\footnotetext{
${ }^{8}$ As noted by K\&R, in nominalizations of external possession the genitive agent appears after the bare NP. I do not have an explanation for this difference between nominal and verbal forms.
} 


\subsection{Pseudo noun incorporation}

The data in the preceding section seem to indicate that the predicate and the possessum are closely connected, but that this connection is not one derived via head movement nor via compounding. Given that the possessum can be phrasal, I conclude that the bare noun in external possession is an instance of pseudo noun incorporation (Massam 2001). Under this approach, the main predicate takes an NP as its complement and this NP is phonologically phrased with the predicate. ${ }^{9}$ Under the right phonological conditions (see above), bonding may occur. And no adverbs may be inserted between the two. ${ }^{10}$ A typical example is illustrated below (see the next section for discussion of the position of the possessor).
a. Fotsy nify Rabe.
white tooth Rabe
'Rabe is white-toothed.'

b.

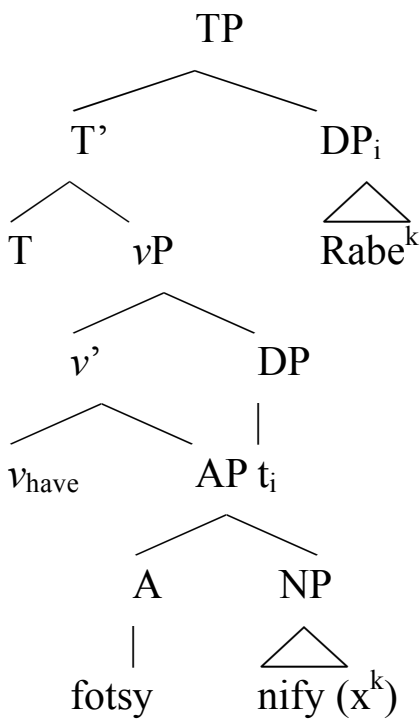

In order to account for the position of the genitive agent of transitive verbs (as in (12b)), I assume PF lowering. That is, in the syntax proper the genitive agent is in [Spec, vP], but there is PF movement to the post-verbal position. Such movement is motivated by the fact that genitive

\footnotetext{
${ }^{9}$ As an NP (and not a DP), the possessum does not have any case features that require checking.

${ }^{10}$ To account for adverbs, I assume that they are XPs that are right adjoined to functional projections. That is, they can be adjoined to $v \mathrm{P}$ or TP, but not AP or NP.
} 
agents are phonologically dependent on the verb and undergo a special kind of phonological bonding (what Keenan 2000 calls N-bonding).

In sum, we have seen that bare nouns do indeed incorporate into the predicate in external possession contexts. This incorporation is sometimes signaled by overt phonological incorporation, but in all cases the bare noun and the predicate form a unit that cannot be separated by elements such as adverbs. Data show that this incorporation is not derived via head movement or via compounding and instead I have argued for pseudo noun incorporation. I now turn to the position of the possessor.

\section{External possession}

$\mathrm{K} \& \mathrm{R}$ discuss in great detail the syntactic and semantic characteristics of external possession in Malagasy. First, the relationship between the possessor and the possessum is typically one of inalienable possession (part-whole relationships, kinship terms, commonly possessed items). Some illustrative examples are given in (14) and (15).

$\begin{array}{lll}\text { a. Tsara endrika } & \text { Rasoa. } \\ \text { good appearance } & \text { Rasoa. }\end{array}$

'Rasoa is pretty.'

b. Madio akanjo Rabe.

clean clothes Rabe

'Rabe dresses cleanly.'

[K\&R: $(34 a, d)]$

(15) a. Manety volo an-janany Rabe.

AT.cut hair ACC-child.3(GEN) Rabe

'Rabe cuts his child's hair.'

b. Manala fatorana ny gadra Rabe.

AT.remove bond DET prisoner Rabe

'Rabe removes the prisoner's bonds.' [K\&R: $(60 \mathrm{a}, \mathrm{b})]$ 
Second, the raised possessor is understood to be affected or essentially involved. To illustrate this, consider the contrast between the external possession example in (16b) and its counterpart (16a).

(16) a. Maty ny vadin-dRabe.

dead DET spouse.GEN.Rabe

'Rabe's spouse is dead.'

b. Maty vady Rabe.

dead spouse Rabe

'Rabe is widowed.'

[K\&R: (1)]

(16a) tells the listener something about Rabe's spouse, while (16b) is about Rabe. Therefore (16a), but not (16b), would be appropriate in a context where Rabe himself is dead (much like the English translations given).

As seen in (14) and (15), there are two broad types of external possession, which $K \& R$ distinguish in the following way: raising to subject and raising to object. In (14), the possessor is the subject of the sentence, while the possessum surfaces within the VP. As K\&R point out, there are several tests that neatly divide the VP (or Predicate Phrase) from the subject. For example, negative polarity items such as intsony 'any longer' occur VP finally but before the subject:

(17) Tsy madio akanjo intsony Rabe.

NEG clean clothes longer Rabe

'Rabe no longer dresses cleanly.

The position of the NPI intsony 'any longer' shows that the possessum akanjo 'clothes' is VPinternal. In (15), the possessor is an object and the possessum is also VP-internal, as shown by the NPI placement in (18). 
Tsy manety volo an-janany intsony Rabe.

NEG AT.cut hair ACC-child.3(GEN) longer Rabe

'Rabe no longer cuts his child's hair.'

K\&R also discuss two further cases: raising of genitives and raising of accusatives. Although the term "external possession" does not seem to apply here, I will argue that these examples should receive the same analysis as the ones above. Consider first raising of genitives, as in (19).

a. Maro ny raharaha izay sahaniko.

much DET work REL TT.confront.1SG(GEN)

'The work faced by me is great.'

b. Maro raharaha sahanina aho.

much work $\quad$ TT.confront $1 \mathrm{SG}(\mathrm{NOM})$

'I have much work to face.'

[K\&R: (86)]

We see in (19a) the first person pronoun as a genitive agent on the verb sahanina 'confront'. Recall from section 2 that this is the form that non-AT agents take in Malagasy. In (19b), the pronoun is nominative. Like the "raising to subject" examples above (e.g. (16b)), we have an apparent change from genitive case to nominative. In accusative raising, as illustrated in (20), however, the cases are different.

$\begin{array}{llllll}\text { a. } & \text { Be } & \text { ny } & \text { asa } & \text { manahirana } & \text { ahy. } \\ & \text { big } & \text { DET } & \text { work } & \text { AT.bother } & 1 \mathrm{SG}(\mathrm{ACC})\end{array}$

'The work that worries me is great.'

b. Be asa manahirana aho.

big work AT.bother 1SG(NOM)

'I have a lot of bothersome work.'

[K\&R: (104)] 
In (20a), the pronoun bears accusative case because it is the notional object of the verb manahirana 'bother'. In (20b), the pronoun is the matrix subject and surfaces as nominative. In both (19b) and (20b), the "raised" element is in a dependency with a null element inside a relative clause, hence the term "raising from NP". Moreover, both (19b) and (20b) are associated with semantic effects similar to external possession - the "raised" element is understood as affected or essentially involved. Despite the semantic parallels between the different kinds of raising, these examples at first appear recalcitrant to a unified syntactic analysis, but I will show that they all fall under the proposal given in the next section.

\section{Structure}

In what follows, I argue that external possession uniformly implicates the projection of a null $v$ that corresponds to 'have' in English. The possessor is generated in the rightward specifier of this $v \mathrm{P}$ and the complement of $v$ is either an unaccusative VP or an AP. ${ }^{11}$ Examples of "raising to subject" involve the structure presented in (21b).

$$
\begin{aligned}
& \text { a. Maty vady Rasoa. } \\
& \text { dead spouse Rasoa } \\
& \text { 'Rasoa is widowed.' }
\end{aligned}
$$

b. $\quad \mathrm{TP}$

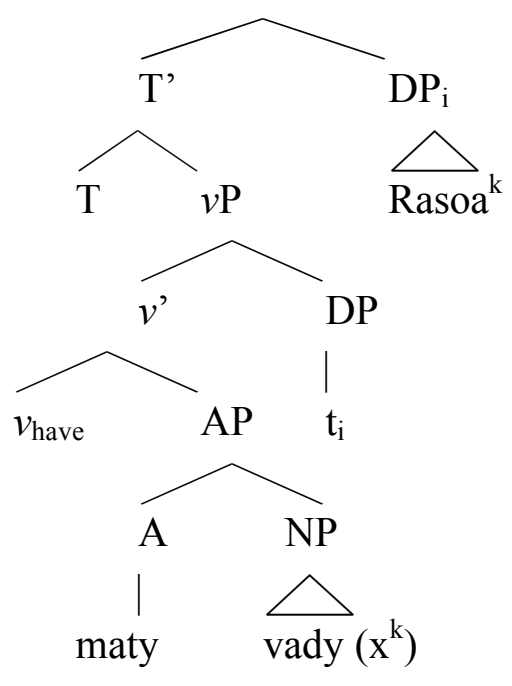

\footnotetext{
${ }^{11}$ Whether or not it is possible to unify these two categories is the subject of future research. In most examples, the complement of $v$ is a category that has only an internal argument.
} 
As is clear from this structure, there is no external possession, per se, given that the possessor is generated outside of the nominal headed by the possessum. The possessive interpretation arises from a binding relationship between the subject and the NP within the predicate. ${ }^{12}$ I follow work by Vergnaud and Zubizaretta (1992), among others, in assuming that inalienable nouns take a possessor argument (x). This argument is bound by the subject Rasoa, as indicated by superscripts. Finally, in the proposed structure, the possessum is an NP sister to the predicate and the resulting structure is an instance of pseudo noun incorporation, as discussed in section 3.

Turning now to external possession to object, the core structure is very similar. In (22), the verb is manety ' cut' and its complement is the bare possessum volo 'hair'. As in (21), the possessor is introduced by a $v$ that corresponds to 'have'. A second $v \mathrm{P}$ is subsequently merged, introducing the agent Rabe.

a. Manety volo an-janany Rabe.

AT.cut hair ACC-child.3(GEN) Rabe

'Rabe cuts his child's hair.'

b.

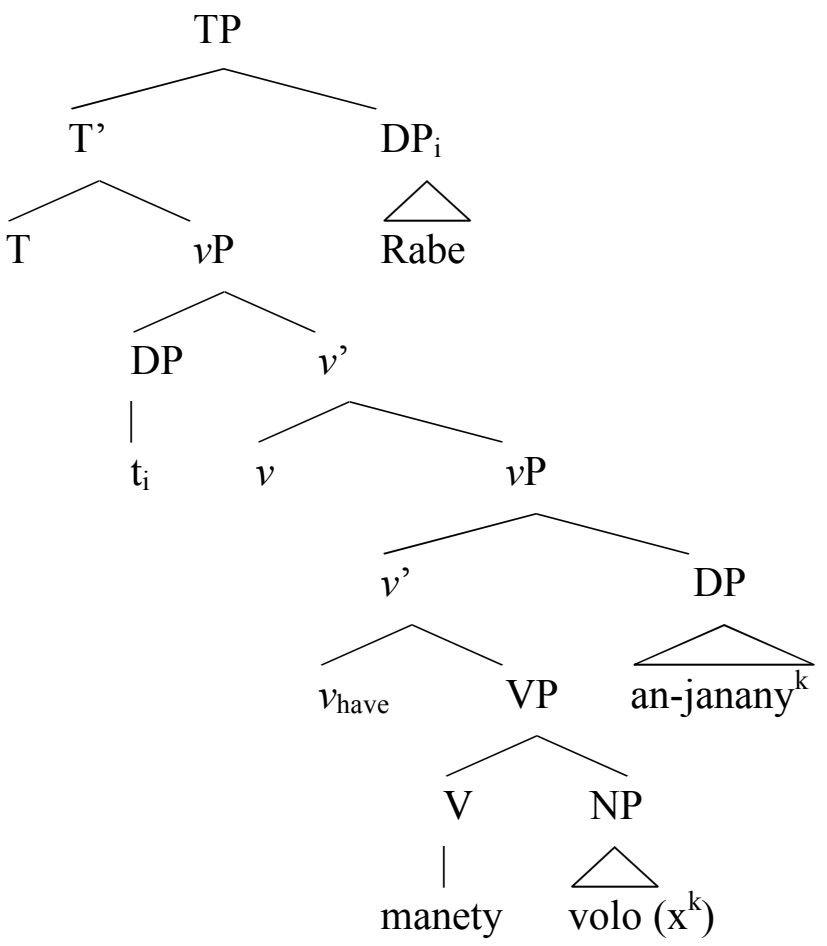

\footnotetext{
${ }^{12}$ The bindee must be null - at this point, I leave this restriction as a stipulation.
} 
Note that in this structure, the closest possible binder for the possessor argument of volo 'hair' is an-janany 'his child', not Rabe, which gives the correct interpretation. ${ }^{13}$ In order to account for accusative case on the possessor, I suggest that the $v$ that introduces the agent also has an accusative case feature, as proposed by Chomsky (1995). Given that manety 'cut' is transitive and can take an accusative object, this assumption is independently motivated. The possessor anjanany 'his child' checks this accusative case feature. ${ }^{14}$ As in all other examples of external possession, the bare NP possessum does not need to check case.

In the proposed structures above, the $v \mathrm{P}$ plays an important role. As mentioned, the $v_{\text {have }}$ introduces an external argument that is not an agent - it is therefore a different $v$ from regular transitive clauses. Moreover, the $v_{\text {have }}$ is associated with a particular meaning, a meaning that is similar to English 'have'. In fact, I suggest that external possession in Malagasy is interpreted parallel to experiencer 'have' sentences in English. The argument introduced by the $v_{\text {have }}$ is

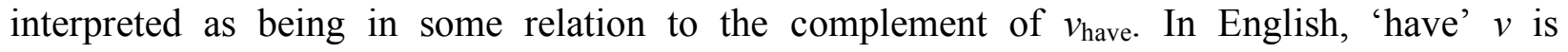
compatible with a wider range of interpretations, including causation, but in Malagasy the only reading is the possessor. I suggest that this explains the affectedness condition noted by K\&R the external argument must be essentially involved in some way in order to receive an interpretation. ${ }^{15}$ And it seems that Malagasy restricts this even further to inalienable possession. Nouns without a possessor argument (alienable nouns) are not possible in external possession:

\footnotetext{
${ }^{13}$ The locality suggests that the binding relationship is syntactic rather than pragmatic. See footnote 15 . Along these lines, it is also not possible to bind the possessor of a possessor:

(i) *Maty vadin'ny rahavavy Rasoa. dead spouse.GEN.DET.sister Rasoa 'Rasoa had her sister's spouse die.'

This may be due to the affectedness constraint or because nouns with (overt) possessors must appear with a determiner.

${ }^{14}$ It is not clear whether or not the accusative object must overtly raise to check case. Given the possible orderings with respect to adverbs, it may be that such raising is optional. See Rackowski and Travis (2000) for discussion of adverb placement in Malagasy.

(i) Manety volo (matetika) an-janany (matetika) Rabe. AT.cut hair (often) ACC-child.3(GEN) (often) Rabe

'Rabe often cuts his child's hair.'

${ }^{15}$ There is some debate in the literature as to whether this link is pragmatic or syntactic. McIntyre (2006) argues for the former, while Harley (1998) concludes it is the latter. Given the impossibility of alienable external possession (23), even with an appropriately rich context (Rasoa loves her bird passionately, Rasoa raises birds for a living, etc.), it seems that in Malagasy the link requires syntactic binding. See also footnote 13.
} 
* Maty vorona Rasoa.

dead bird Rasoa

'Rasoa had her bird die.'

Finally, I note the parallel between the $v$ in external possession and so-called "high" applicatives, discussed by Pylkkänen (2002): both relate an entity and an event. But high applicatives are typically associated with a range of meanings that are absent in Malagasy - in particular, binding of an empty argument is not necessary. It is not immediately clear why Malagasy is so restrictive, but I tentatively suggest this is related to the semantics of $v_{\text {have }}$ in this language. ${ }^{16}$

In the next section I provide arguments for the proposed structure.

\section{Discussion}

\subsection{Against movement}

One of the goals of this paper is to provide a unified analysis of the different types of "raising from NP" discussed by K\&R. Recall the three types: external possession (24a), raising from genitive (24b) and raising from accusative (24c).

$$
\begin{aligned}
& \text { a. Maty vady Rasoa. } \\
& \text { dead spouse Rasoa } \\
& \text { 'Rasoa is widowed.' }
\end{aligned}
$$

b. Maro raharaha sahanina aho.

much work TT.confront $1 \mathrm{SG}(\mathrm{NOM})$

'I have much work to face.'

[K\&R: (86)]

$\begin{array}{llll}\text { c. } & \text { Be asa manahirana } & \text { aho. } \\ \text { big work } & \text { AT.bother } & 1 \mathrm{SG}(\mathrm{NOM})\end{array}$

'I have a lot of bothersome work.'

[K\&R: (104)]

\footnotetext{
${ }^{16}$ Note that the $v_{\text {have }}$ for external possession cannot be merged higher than the agent in "raising to object" examples, such as (22). If it were merged in this high position, it would be block movement of the agent to subject position and it would not get case ( $v_{\text {have }}$ is not a case position). I take $v_{\text {have }}$ 's merge position to be determined by selection: $v_{\text {have }}$ selects a lexical category, not another $v$.
} 
Because of the very different structures in these three types of "raising", I reject a movement analysis (i.e. an analysis where the sentences in (24) are derived from their non-raised counterparts). In particular, in the cases of raising from genitive and from accusative, such movement would violate the complex NP constraint - both involve movement from within a relative clause. Moreover, given the diverse nature of the different kinds of raising from NP (from possessor, from genitive agent, from accusative) a unified movement analysis is impossible: there is no single base position from which movement occurs.

As an alternative to movement, I suggest that what unifies these three constructions is binding. In each case, the subject binds an empty element: a possessor, an agent or a theme. In other words, in each example in (24), the subject binds an unrealized argument position. In (25), I provide the structure underlying $(24 \mathrm{c})$. The empty argument position is within the relative clause that modifies the noun asa 'work' - it corresponds to the object of the verb manahirana 'bother'.

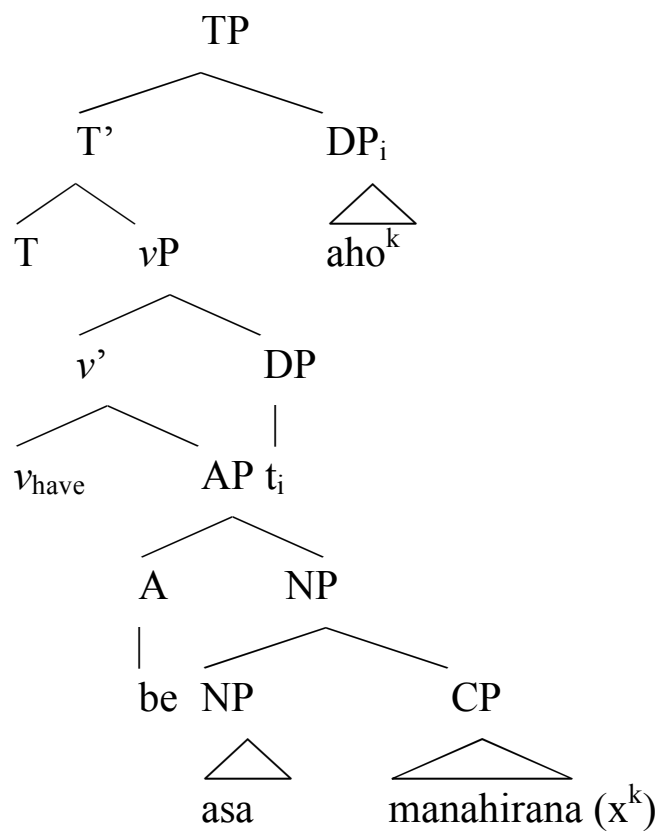

What unifies the various kinds of "raising" are two elements: the presence of a $v$ that introduces an extra argument and an empty argument position that needs to be bound. Moreover, recall that the argument introduced by $v_{\text {have }}$ is interpreted as somehow related to the event and that this 
relationship in Malagasy requires binding and an affectedness reading. The proposed analysis captures the broad semantic range of the various cases of "raising" discussed by K\&R.

\section{2 'Tough' movement?}

Before concluding, I would like to discuss the parallels between the data discussed in this paper and 'tough' constructions in English and ask whether an analysis along the lines of 'tough' movement is possible. ${ }^{17}$ Although such an analysis is initially appealing, a quick glance at the Malagasy facts shows that external possession cannot be a kind of 'tough' construction. First looking at the similarities, in both cases, we have a subject that does not appear to have a theta role, but is instead linked to a theta position, either via movement or binding (e.g. of an empty operator - Chomsky 1977).

(26) a. John is tough Op $p_{i}$ PRO to please $t_{i}$.

b. Maty vady $\left(x^{i}\right) R^{i}$ abe

dead spouse Rabe

'Rabe is widowed.'

Malagasy also has 'tough' movement - what is crucially different from external possession is that there is an overt signal of movement within the embedded clause. The embedded verb is marked for voice, indicating that something (possibly an operator) has been extracted from the embedded clause.

(27) Sarotra vakina ity boky ity.

hard TT.read this book this

'This book is hard to read.'

[Keenan 1976: (125c)]

In (27), the embedded verb, vakina 'read' is marked for Theme Topic, the voice morphology used when a theme is the subject or has been extracted. In external possession, on the other hand, the lower verb does not show the voice alternations one would expect if there were movement from the relevant position.

\footnotetext{
${ }^{17}$ Thanks to an anonymous reviewer for pointing out the relevance of 'tough' movement.
} 
Be asa manahirana aho.

big work AT.bother $1 \mathrm{SG}(\mathrm{NOM})$

'I have a lot of bothersome work.'

[K\&R: (104)]

If there were movement from the object position of manahirana 'bother', the verb would be in Theme Topic voice (sahiranina), much like in (27). Since this is not the case, I reject a 'tough' movement analysis of external possession.

\subsection{A puzzle about bare nouns}

In the analysis presented above, I claim that the possessum is an NP in the syntax, a bare noun. What is the status of bare nouns in Malagasy? First, it is important to note that in cases of external possession, no determiners or demonstratives are possible on the possessum.

$$
\begin{array}{ll}
\text { Maty (*ny) vady } & \text { Rabe. } \\
\text { dead (DET) spouse } & \text { Rabe } \\
\text { 'Rabe was widowed.' }
\end{array}
$$

[K\&R: (15a)]

This restriction differs from direct objects, which may be bare or may appear with a determiner (i.e. they may be NPs or DPs).

(30) Manana (ilay) vola aho. AT.have (DEF) money 1SG(NOM)

'I have (the previously discussed) money.'

Thus it appears that external possession creates a kind of Definiteness Restriction, similar to existential constructions. ${ }^{18}$

\footnotetext{
${ }^{18}$ I do not have an explanation for the Definiteness Restriction, though it may be linked to the null 'have' proposed in the structure above.
} 
As for the interpretation of the bare noun, there are two basic types. The first type is in idiomatic external possession. K\&R note that many examples of external possession are not interpreted literally.

a. Lava tongotra izy.

long foot $3(\mathrm{NOM})$

'He is always on the move.'

(lit. 'He has long feet.')

b. Fotsy varavarana i Soa.

white door Soa

'Soa is never at home.'

[K\&R: $(38 \mathrm{~d}, \mathrm{e})]$

(lit. 'Soa has a white door.')

In these cases, the bare noun is clearly non-referential. The second type of external possession is interpreted literally. In these cases, the bare noun is referential. For example, (29) presupposes the existence of Rabe's spouse. Moreover, these bare nouns are active in the discourse and may be referred to by pronouns in subsequent utterances. ${ }^{19}$

a. Roa lela ny antsipikany. Tena maranitra izy ireo.

two blade DET knife.3(GEN) really sharp 3.NOM PL

'His pocketknife is two-bladed. They are really sharp.'

b. Maty filoha ny firenena. Efa antitra izy.

dead president DET country already old 3(NOM)

\footnotetext{
${ }^{19}$ Note that these judgements differ from what K\&R report. They claim that the bare noun cannot antecede a pronoun, as in (i).

(i) * Maty vady Rabe. Efa antitrantitra izy. dead spouse Rabe already oldish 3(NOM)

'Rabe was widowed. She was already oldish.' [K\&R: (16b)]

My consultants agree with the judgement in (i), but changing the example improves the possibility of coreference, as in (32). I think the problem with (i) is more pragmatic - there are two animate DPs that could possibly be the antecedent and nominative pronouns preferably refer back to nominative DPs. In (32), on the other hand, world knowledge makes it clear which DP is being referred to, allowing accomodation.
} 
'The country's president died. She was already old.'

The bare noun remains referential even under negation.

$\begin{array}{lll}\text { Tsy maty filoha ny firenana. Sitrana } & \text { izy. } \\ \text { NEG } & \text { dead president DET country cured } & \text { 3(NOM) }\end{array}$

'The country's president didn't die. She is cured.'

This is in contrast to bare noun objects in Malagasy, where the noun is unable to serve as the antecedent to a pronoun if under negation.

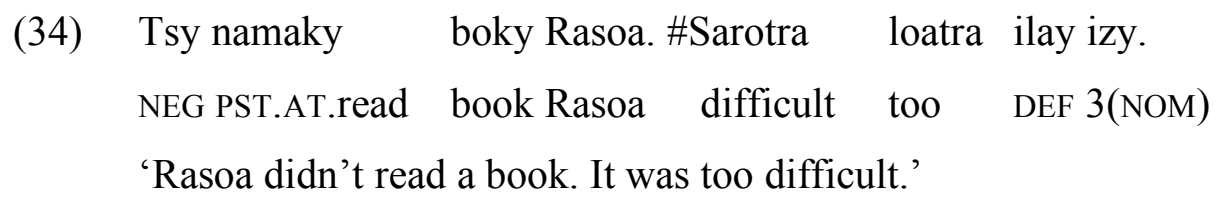

I suggest that the referential transparency of bare nouns in external possession stems from the presence of the null 'have' verb. In particular, $v_{\text {have }}$ introduces an existential quantifier that binds the bare noun. Note that Massam (2001, this volume) argues for something similar; in her analysis of existential pseudo noun incorporation, the existential verb confers a referential feature on its complement. In other words, it is particular semantic properties of the verb that ensure the referentiality of the bare noun.

The bare nouns in external possession contexts otherwise act like bare plurals in English in terms of scope. As noted by Carlson (1977), bare plurals in English also always take narrow scope.

(35) a. Everyone read books on caterpillars.

b. John saw dogs on his lawn at 3, 4:30, 6 and 7:15.

Data from $K \& R$ show that bare nouns in Malagasy obligatorily scope under adverbs such as indroa 'twice' and lalandava 'always'. 
a. Maty vady indroa Rabe. dead spouse twice Rabe 'Rabe was widowed twice.' not 'Rabe's spouse died twice.'

b. Marary zanaka lalandava Rabe. sick child always Rabe 'Rabe always has a sick child.' not 'Rabe's child is always sick.'

These scope facts are the same with other bare nouns in Malagasy, as illustrated in (37).

a. Namaky boky indroa Rabe. PST.AT.read book twice Rabe 'Rabe read a book twice.' (not the same book)

b. Nianatra lesona lalandava Rasoa. PST.AT.study lesson always Rasoa 'Rasoa always studied a lesson.' (not the same lesson)

The example in (38) shows that if the object has a determiner, wide scope is possible (and in fact is the only reading).

$\begin{array}{lllll}\text { Mamaky } & \text { ny boky } & \text { roa } & \text { lalandava } & \text { Rabe. } \\ \text { AT.read } & \text { DET book two } & \text { always } & \text { Rabe }\end{array}$

'Rabe always reads two books.' (the same two books)

Much more research is required on nominal interpretation and scope in Malagasy, but I believe the analysis presented in this paper may account for the seemingly contradictory interpretation of bare nouns in external possession contexts. I suggest that the wide scope with respect to negation

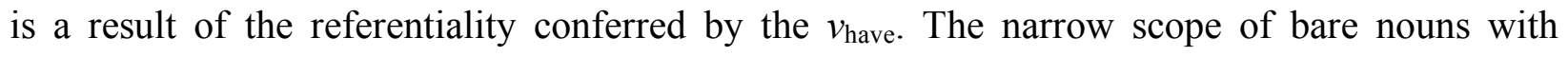


respect to other adverbs, however, is due to their bare noun status. Why adverbs and negation, which are typically treated on a par as scopal elements, differ just in these instances is left for future research.

\section{Conclusion}

In Malagasy external possession the possessum surfaces as a bare noun and appears to incorporate into the predicate. I have shown, however, that this is not syntactic or lexical incorporation. Instead, as a bare noun, the possessum exhibits syntactic and phonological dependence on the predicate - it cannot be separated from the predicate by adverbs and the phonological rule of bonding may apply. On the other hand, the bare noun can be phrasal and can be separated from its host by a genitive agent. Semantically, the bare noun possessum is referentially active although it takes narrow scope with respect to adverbs. These properties are all hallmarks of existential pseudo noun incorporation (Massam 2001, this volume). ${ }^{20}$

In this paper, I have also argued that external possession in Malagasy does not in fact involve raising of a possessor. Instead, the possessor is generated in the specifier of a $v \mathrm{P}$ and binds an argument position of an element within the complement to the $v \mathrm{P}$. Note that the proposed structure is very similar to analyses of English 'have' (Ritter and Rosen 1997, Harley 1998). As has long been recognized, 'have' has many readings, including what is sometimes called the experiencer reading.

Asterix had Obelix drop a menhir on him.

Ritter and Rosen (1997) and Harley (1998) argue that the interpretation of 'have' is determined by the nature of the relationship between its subject and complement. The experiencer reading arises when the complement of 'have' is a predicate and there is a binding relationship between the subject of 'have' and material in the complement. According to these analyses, 'have' is a type of light verb that expresses a relationship between an entity (the possessor) and either an entity or a situation. In this paper, I have proposed that Malagasy has a null equivalent to 'have'

\footnotetext{
${ }^{20}$ As noted by Massam (this volume), pseudo noun incorporation is typically used for institutionalized activities or states. Existential pseudo noun incorporation in Niuean and external possession in Malagasy, however, are not associated with such interpretation, further indicating the parallels between these two constructions.
} 
that relates an entity and a situation. ${ }^{21}$ In this way, external possession is a kind of high applicative construction (Pylkkänen 2002). In fact, similar analyses of external possession in languages such as German have been proposed by Lee-Schoenfeld (2006) and McIntyre (2006). Thus we can account for a cluster of syntactic phenomena in different languages using a single underspecified head. Crucially these phenomena involve similar semantic effects, including possession, affectedness and stativity.

Thus the range of properties associated with external possession in Malagasy is due to two aspects of the syntactic structure: the null $v_{\text {have }}$ and the bare noun (NP) status of the possessum.

\section{References}

Baker, Mark. 1988. Incorporation: A theory of grammatical function changing. Chicago: University of Chicago Press.

Bell, Sarah. 1983. Advancements and ascensions in Cebuano. In D. Perlmutter (ed.), Studies in Relational Grammar 1, 143-218. Chicago: University of Chicago Press.

Borer, Hagit and Yosef Grodzinksy. 1986. Syntactic cliticization and lexical cliticization: The case of Hebrew dative clitics. In H. Borer (ed.), Syntax and semantics 19: 175-217. New York: Academic Press.

Carlson, Greg. 1977. Reference to kinds in English. PhD thesis, UMass Amherst. (Published 1980, New York: Garland.)

Chomsky, 1977. On wh-movement. In P. Culicover, T. Wasow and A. Akmajian (eds.), Formal syntax, 71-132. New York: Academic Press.

Chomsky, Noam. 1995. The minimalist program. Cambridge, MA: MIT Press.

Guilfoyle, Eithne, Henrietta Hung and Lisa Travis. 1992. Spec of IP and Spec of VP: Two subjects in Austronesian languages. Natural Language and Linguistic Theory 10: 375-414.

Harley, Heidi. 1998. You're having me on! Aspects of have. In J. Guéron and A. Zribi-Hertz (eds.), La grammaire de la possession, 195-226. Nanetter: Publedix.

Kayne, Richard. 1994. The antisymmetry of syntax. Cambridge, MA: MIT Press.

Keenan, Edward. 2000. Morphology is structure: A Malagasy test case. In I. Paul, V. Phillips and L. Travis (eds.), Formal issues in Austronesian linguistics, 27-47. Dordrecht: Kluwer.

\footnotetext{
${ }^{21}$ Malagasy also has a lexical verb that expresses ownership, manana 'have', and the existential verb misy can also be used to express certain kinds of inalienable possession (see Paul 1998 for discussion.)
} 
Keenan, Edward. 1976. Remarkable subjects in Malagasy. In C. Li (ed.), Subject and topic, 249301. New York: Academic Press.

Keenan, Edward and Maria Polinksy. 1998. Malagasy morphology. In A. Zwicky and A. Spencer (eds.), Handbook of morphology, 563-624. Oxford: Oxford University Press.

Keenan, Edward and Baholisoa Ralalaoherivony. 2000. Raising from NP in Malagasy. Lingvisticae Investigationes 23: 1-44.

Landau, Idan. 1999. Possessor raising and the structure of VP. Lingua 107: 1-37.

Lee-Schoenfeld, Vera. 2006. German possessor datives: raised and affected. Journal of Comparative Germanic Linguistics 9: 101-142.

Massam, Diane. 2006. Deriving inverse order. Ms., University of Toronto.

Massam, Diane. 2001. Pseudo noun incorporation. Natural Language and Linguistic Theory 19: 153-197.

Massam, Diane. 2000. VSO is VOS: Aspects of Niuean word order. In A. Carnie and E. Guilfoyle (eds.), The syntax of verb initial languages, 97-117. Oxford: Oxford University Press.

Massam, Diane. 1985. Case theory and the projection principle. $\mathrm{PhD}$ thesis, MIT.

McIntyre, Andrew. 2006. The interpretation of German datives and English have. In D. Hole, A. Meinunger and W. Abraham (eds.), Datives and other cases, 185-211. Amsterdam: John Benjamins.

Mithun, Marianne. 1984. The evolution of noun incorporation. Language 60: 847-894.

Paul, Ileana. To appear. Bare nouns in the typology of DPs. Linguistica Atlantica.

Paul, Ileana. 1998. Existentials and partitives in Malagasy. Canadian Journal of Linguistics 43: 377-409.

Payne, Doris and Immanuel Barshi (eds.). 1999. External possession. Amsterdam: John Benjamins.

Pearson, Matt. 2005. The Malagasy subject/topic as an A-bar element. Natural Language and Linguistic Theory 23: 381-457.

Pearson, Matt. 2001. The clause structure of Malagasy: A minimalist approach. PhD thesis, UCLA.

Pylkkänen, Liina. 2002. Introducing arguments. $\mathrm{PhD}$ thesis, MIT. 
Rackowski, Andrea and Lisa Travis. 2000. V-initial languages: X or XP movement and adverbial placement. In A. Carnie and E. Guilfoyle (eds.), The syntax of verb initial languages, 117142. Oxford: Oxford University Press.

Rajemisa-Raolison, Régis. 1971. Grammaire malgache. Fianarantsoa: Librairie Ambozontany.

Ritter, Elizabeth and Sara Thomas Rosen. 1997. The function of have. Lingua 101: 295-321.

Rosen, Sara Thomas. 1989. Two types of noun incorporation: A lexical analysis. Language 65: 294-317.

Thiersch, Craig. 2006. Three systems of Remnant Movement II and extraction from specifier position. In H.-M. Gärtner, P. Law and J. Sabel (eds.), Clause structure and adjuncts in Austronesian languages, 233-280. Berlin: Mouton de Gruyter.

Travis, Lisa. 2001. Derived objects in Malagasy. In W. Davies and S. Dubinsky (eds.), Objects and other subjects: Grammatical function, functional categories and configurationality, 123155. Dordrecht: Kluwer.

Van Geenhoven, Veerle. 2002. Raised possessors and noun incorporation in West Greenlandic. Natural Language and Linguistic Theory 20: 759-821.

Vergnaud, Jean-Roger and Maria Luisa Zubizarreta. 1992. The definite determiner and the inalienable constructions in French and English. Linguistic Inquiry 23: 595-652. 